\title{
editorial
}

\section{Is archaeology useful? An archaeological dialogue}

For a third time, Archaeological dialogues has organized a face-to-face dialogue at an international conference around a current and provocative question. At the annual meeting for the Society of American Archaeologists in Atlanta, USA, in April 2009, Archaeological dialogues invited a panel of leading scholars to participate in a discussion forum entitled 'Is archaeology useful?'. The discussion sought to address a number of interrelated questions: how important is the criterion of 'usefulness' in establishing the value of our discipline? To whom do we need to justify ourselves? In what ways can or should archaeology be useful to society? Must archaeologists distinguish between critique and action, and balance knowledge production and public consumption of our work? Does it really matter what we do and for whom? Shannon Dawdy presented her thoughts in a keynote address which was followed by comments from Carol McDavid, Peggy Nelson, Mark Pluciennik, Jeremy Sabloff, Joe Watkins and Rita Wright. The keynote address, along with the comments that arose from the forum, are published in this issue as a discussion article. The written version of this dialogue also includes comments by Pedro Funari with Aline Vieira de Carvalho, Cornelius Holtorf and Ulrike Sommer, who were invited to share their views on the topic and broaden the scope of the debate.

\section{Archaeology, use and value}

Whether for reasons of funding, out of political conviction or personal satisfaction, and as a response to government pressure and 'public opinion', many archaeologists today are concerned to make their practice 'useful'. As members of a discipline bridging the gaps between the natural sciences, humanities and social sciences, archaeologists frequently attempt to justify the investment of resources (both public and private) in their endeavour on the grounds that they can offer important insights into a number of arenas deemed significant, such as sustainable development, interethnic relations, minority rights and so on. In recent years there has been a significant movement to make archaeology explicitly 'useful' in society and also to communicate this role of archaeology to others. This has been especially significant within the continuously growing field of public archaeology. And while the question asked at the discussion forum may appear provocative to some, it was also pointed out in the discussion that this question has been debated frequently in recent years, and some may even consider the case closed. Archaeology is 
'useful'. However, by stating the title of the forum as an open question, we wanted to include other ways of assessing the place for archaeology in society. Indeed, in the debate it is clear that some take the view that the presumed social value of actions in the contemporary world can be more efficiently and effectively accomplished outside the discipline of archaeology. For many looking to defend the usefulness of archaeology, the question often turns to its special contribution as either critique, practical action or knowledge production, or some combination of all three. Moreover, the question asked at the forum could also be viewed as a way of calling into question the very idea of usefulness as a measure of value and a tool for validation. Finally, while this debate takes place within the discipline itself, an increasing number of outsider voices challenge the authority of archaeology in favour of alternative interpretations of the past. In what ways does this threaten claims that the greatest value of archaeology is its participation in and support for free intellectual enquiry, as a societal good in itself?

\section{Archaeology and its public}

One of the dominant themes in this forum centred on the nature of archaeology's public, how it is cultivated and satisfied with an eye towards ethical practice and responsible consequences. The question we might ask, then, is, is all archaeology public archaeology? Here the relation of the discipline to the aims and outcomes of a broader heritage industry requires a close examination of how archaeology draws from its colonial and imperial legacies and the authority that it exerts in differentiating between stakeholder communities. As the past emerges as both a valued and a valuable resource, these communities play a vital role in responding to the question of archaeology's potential utility.

The outcome of this exchange, we hope, is a stimulating dialogue that gets to the core of contemporary archaeology and its most pressing challenges today. The editors welcome correspondence by mail or e-mail, but also encourage the readers to share their views through the Cambridge University Press comments feature online at the Archaeological dialogues page, where many of you will have downloaded this forum (http://journals.cambridge.org/ action/displayJournal?jid=ARD). 